\title{
浅谈新型绿色节能技术在建筑工程施工中的应用
}

\author{
陆 宽* \\ 齐齐哈尔市华宇建筑工程有限公司，黑龙江 161000
}

\begin{abstract}
摘要: 随着现代建筑行业的迅速发展, 新型绿色节能技术在建筑工程施工中被广泛应用。新型绿色节能技术不 仅帮助建筑工程提升节能环保, 也解决了建筑工程资源紧缺的现象, 并且提高了工程的质量, 最终实现了环保这一问 题。因此新型绿色节能发展在当今社会中成为最重要的一部分, 本文就这一话题对绿色节能技术在建筑工程施工中的 应用进行研究和探讨。
\end{abstract}

关键词：新型绿色节能技术；建筑工程；应用

\section{Application of New Green Energy Saving Technology in Construction of Building Engineering}

\author{
Kuan $\mathrm{Lu}^{*}$ \\ Qiqihar Huayu Construction Engineering Co., Ltd., Qiqihar 161000, Heilongjiang, China
}

\begin{abstract}
With the rapid development of modern construction industry, new green energy-saving technology is widely used in construction engineering. The new green energy-saving technology not only helps the construction engineering to improve energy conservation and environmental protection, but also solves the shortage of construction engineering resources, improves the quality of the project, and finally realizes the problem of environmental protection. Therefore, the development of new green energy-saving technology has become the most important part in today's society. This paper studies and discusses the application of green energy-saving technology in construction engineering on this topic.
\end{abstract}

Keywords: New green energy saving technology; building engineerin; application

\section{一、前言}

目前看来, 经济的迅速发展使人们的生活变得更加富裕, 然而生活要求也在逐渐提高, 对环境要求更是严格。所 以, 要实现人们所处的生活环境都保证在绿色节能环保建筑当中 ${ }^{[1]}$ 。因此, 为了实现绿色节能发展, 实现个性化绿色 设计, 建筑工程实行了一系列的政策, 并在建筑设计上进行全方位考虑, 不仅考虑绿色节能的问题上, 还要考虑它的 功能以及质量都能够保证生命周期, 并且还要减少其他因素出现的一系列问题 ${ }^{[2]}$ 。所以, 建筑工程实施绿色节能环保 问题要实际加强，让新型绿色节能技术在建筑工程中得到进步与发展。

\section{二、新型绿色节能技术在建筑工程中的特点}

绿色节能技术的发展让建筑工程也能够持续发展, 建筑工程也在不断地作自身发展规划, 使得建筑工程要在环保 问题上加强实施, 从而减轻传统的工业对环境造成的影响 ${ }^{[3]}$ 。因此, 绿色节能技术进行逐步推进, 在这当中, 新型绿 色节能技术在建筑工程上的主要特点如下:

\section{(一) 使用生命周期长}

在建筑工程中, 使用绿色节能技术要考虑它的使用周期, 在它材料的使用以及施工技术上, 并且后期会出现的 维修和保养, 都极大地影响了建筑工程使用周期的长短 ${ }^{[4]}$ 。但在这一过程中, 要确定绿色节能技术在建筑上的使用周 期，还要对建筑过程中所产生的废物利用问题进行处理，因为这一问题，对整个建筑工程起到很大的作用。

*通讯作者: 陆宽, 1987年11月, 男, 汉族, 黑龙江省齐齐哈尔市人, 现任齐齐哈尔市华宇建筑工程有限公司副 总经理兼技术负责人, 中级工程师，本科。研究方向：土木工程。 


\section{（二）具有重要的环保理念}

绿色节能技术对于建筑上来说, 传统的建筑工程是需要实际的理论与技术才能得出结果进行实际的绿色节能实 施，在这当中，每个地区的要求都是节能技术是否可以实现保护功能，对当地的自然环境是否产生了一定的影响 ${ }^{[5]}$ 。 因此, 在绿色节能环保技术的这一发展上要做到最重要的一条标准, 那就是符合当地建筑的环境问题, 而且要把自然 环境作为重点保护, 然后在建筑过程中要使用的材料必须是对环境影响最小的, 进而才能做到保护环境, 并且还能提 升建筑工程上的节能技术发展。

（三）改善环境、节约能源

目前的环境污染厚实人们自身造成的, 由于不正确的使用采暖方法, 曾经大量的烧煤取暖, 煤炭释放出的二氧化 碳极大地增加了温室效应 ${ }^{[6]}$ 。因此, 现在推动的各种新型绿色技术，比如：太阳能技术、节能保温技术、地源热㫤技 术和墙屋保温技术已被应用到各个建筑当中, 因此在建筑中开始逐步进行实施, 不仅节约了工程上能源的消耗, 而且 还大大提升了人们的生活环境保护以及大气环境的保护。

建筑上通常是一个高消耗的工程, 对土资源、矿资源以及水资源和电能都消耗巨大, 所以, 要在建设过程中及时 地节省能源, 提倡可再生能源的使用和水循环的利用, 建筑进行合理的设计后也要进行积极保护, 最终能达到绿色能 源使用的真正目的，推动建筑行业的可持续发展。

\section{三、新型绿色节能技术在建筑工程中的应用}

传统的建筑工程在建筑材料上的使用是需要大量资金和技术来投人的，而且随着建筑的发展，工程后期的维修以 及保养问题都需要损耗大量资金, 因此, 这一问题严重影响建筑经济发展, 所以这一传统建筑工程不利于建筑工程长 远的发展。但是, 自从绿色节能技术的推出, 建筑工程的经济就因此得到了很大的提升, 主要是建筑工程积极使用绿 色环保材料, 实际的经济投人比传统的少 ${ }^{[7]}$; 绿色节能技术适应各地区的环境保护, 进行完善的角度考虑, 绿色节能 技术对此问题也降低了经济支出, 把建筑工程整体的经济都提高了。所以，新型绿色技术在建筑工程上的应用具体图 表1如下。

表1 新型绿色技术在建筑工程节约计划

\begin{tabular}{|c|c|c|c|}
\hline 节约项目 & 目标计划 & 节约成本 & 用量计划 \\
\hline 太阳能技术 & 太阳能转换电能 & $30 \%$ & 节约成本为前提 \\
\hline 节约门窗和玻璃 & 空气流通及供热 & $40 \%$ & 节约成本为前提 \\
\hline 保温墙技术 & 增强整体保温性 & $25 \%$ & \\
\hline 保温屋技术 & 隔热保温效果 & $30 \%$ & 节约成本为前提 \\
\hline 地源热原技术 & 调节室内温度 & $20 \%$ & \\
\hline 水循环利用技术 & 环保性、经济性 & $35 \%$ & \\
\hline
\end{tabular}

(一) 应用太阳能技术

在建筑工程上，对于太阳能技术的应用并不陌生，因为利用太阳能技术可以将发电装置通过太阳能的无污染以及 可再生能源转换成电能, 并供应人们的生活保证了产生的电力能够使日常生活的正常运转, 寒冷天气时还能够解决供 暖方面的问题。因此, 太阳能除了具有可再生与无污染的优点外, 它还具有快捷的作用并且不具备能源消耗以及成本 问题 ${ }^{[8]}$ 。因此, 建筑工程要积极对太阳能技术进行研究, 从而能够更好地利用这一可再生能源, 最终还能达到节能环 保这一重要理念。所以, 要加强各地区的气候与环境问题进行太阳能的合理利用, 从而降低建筑工程上的能源消耗问 题，最终能够实现真正的绿色环保技术。

（二）应用节能门窗和节能玻璃技术

在建筑工程上节能门窗和节能玻璃的应用越来越广泛。建筑工程的维护最重要的一部分就是节能门窗与节能玻 璃, 因为它能够对建筑物的室内以及室外都能进行有效的空气流通和热量的供应, 因此, 建筑物的节能门窗和技能玻 璃的保温和隔热能够对建筑工程的能源产生极大的消耗 ${ }^{[9]}$ 。因为门窗和玻璃是建筑工程施工中比较脆弱的地方, 并且 能源的消耗占到整个建筑的 $35 \%$ 。因此, 根据整个建筑工程的需求, 需要及时的应用节能玻璃与门窗, 能够极大地增 强建筑围护的结构中的保温和隔热，最终减少能源的损耗问题。

（三）应用保温墙体技术 
保温墙体在建筑工程中是能够直接影响建筑物的施工的质量问题, 建筑工程目前主要增强墙体的保温性。目前, 外部保温、中部保温和外部保温是建筑工程中绿色节能技术主要应用的保温墙体, 因为内部保温和中间保温会很大 程度上影响着建筑墙面的主体问题, 而且不仅施工不方便, 也不方便进行墙面的装饰, 但是外部保温可以避免这一现 象, 因此, 外部保温技术在建筑中最为广泛的应用。在实施绿色节能工程的时候, 就要加强保温墙体的研究, 根据不 同的情况选用合理的墙体, 而且还需要考虑性价比及保温性能。比如建筑工程中会用到的材料有硅酸铝、无机保温砂 浆、玻璃棉和挤塑板等这些都是常用的保温材料, 所以, 必须根据不同的墙体选择合适的保温材料, 而且必须是具有 高技术水平或者专业人员进行严格施工规范要求进行操作, 这样不仅能极大地降低保温材料的损耗, 还能实现保温墙 体的真正作用。

（四）应用保温屋面节能技术

目前建筑工程的施工上, 大多数人都会选择使用节能屋面技术。因为传统的屋面技术没有节能屋面技术产生的保 温隔热效果好, 而且节能屋面技术还能够极大地提升施工过程上的工作效率, 还能够进行简单的操作。并且在节能保 温屋的使用周期和雨水袭击中承受阳光直射还存在了很大的优势, 在节能保温屋的施工上, 要用到的材料是泡沫混凝 土和硬质聚氨酝, 使用这两者材料是为了达到节能环保的目的, 也能使屋面的保温性极大地增强, 使室内的温度能够 达到合适的温度，从而使人们能够居住的更具舒适性。

（五）应用地源热百节能技术

因为地源热洜技术对调节室内温度有很好的作用, 这就能够在建筑工程上应用地源热葲技术从而减少能源的损 耗。因此还要根据不同的地区环境以及建筑施工的合适位置才能对地源热原技术进行合理地使用。地源热百技术的应 用在最炎热的天气中吸收屋内高温因素, 寒冷的时候又可以向室内提供大量的热量, 让室内一直都能够处于最合适的 温度范围，这样人们居住的就会更舒适。

(六) 应用水循环技术

在建筑工程上, 避免不了会有各种污水的排出, 但是解决污水的问题是要投人大量资金的, 但是有时污水处理的 不到位就又影响了环境的环保问题。因此, 利用水循环技术就能够达到水资源的训话利用, 这样一来就能达到真正的 水资源节约, 还对建筑工程的环保问题进行了解决, 使建筑工程的经济效益不被损害。具体的做法包括: 可以在施工 过程中进行抽水, 然后把水储集起来应用在生活或者工程中; 还有一个办法就是可以把雨水回收技术利用到收集雨水 中去, 用来洗车或者冲则所等等。水资源的循环利用能够极大地提升工程的环保与经济性。

\section{四、结语}

综上所述, 建筑行业要想稳定的发展, 就必须积极实现节能环保的理念, 然而顺应时代的潮流, 在房屋的建造上 提升新型绿色技能技术的实际应用, 可以有效地降低建筑能源的损耗, 提高人们的生活环境, 还能够对建筑企业经济 效益的发展有着重要作用。因此加大新型绿色节能技术的研究, 提高建筑工程的水平从而降低能源消耗现象, 按照绿 色节能技术要求进行规范操作，提升绿色节能技术的质量同时也保证了建筑工程实施的真正含义。

\section{参考文献:}

[1]石昕.绿色节能技术在公共建筑幕墙设计中的应用[J].砖瓦, 2020(10):89-90.

[2]刘东栋,金淙立, 朱嘉浩, 张蓁䜭. 高校既有建筑改造的绿色节能技术应用策略研究 [J]. 安徽建筑, 2020,27(08):143-145.

[3]李延珠,刘敏.绿色节能技术在民用建筑电气设计中的应用浅析 [J].电气技术与经济, 2020(03):6-7+18.

[4]刘伟.绿色节能技术在公共建筑幕墙设计中的应用 [J].绿色环保建材, 2020(05): $43+45$.

[5]杨鹏宇.建筑门窗幕墙绿色节能技术在实际中的应用探讨[J].居舍, 2020(07):63.

[6]梁荣海,黄婵娟.建筑门窗幕墙中的绿色节能技术研究[J].低碳世界, 2019,9(12):133-134.

[7]陆冬飞.新型绿色节能技术在建筑工程施工中的应用分析[J]. 内蒙古煤炭经济, 2019(23):204.

[8]宋志凌.建筑工程设计中的绿色节能技术应用探究[J]. 门窗, 2019(21):7+9.

[9]李笁华.绿色节能技术在民用建筑电气设计中的应用分析[J].地产, 2019(20):43-44. 